\title{
A STUDY OF THE TOXIC CAUSES OF CARDIAC ARREST IN OVERDOSED PATIENTS PRESENTED TO MANSOURA EMERGENCY HOSPITAL FROM MARCH 2008 TO MARCH 2010
}

\author{
BY \\ A. A. Ghanem, A. M. Attia, O.A. Shabka \\ Department of Forensic Medicine and Clinical Toxicology \\ Faculty of Medicine, Mansoura University
}

\begin{abstract}
Toxic cardiac arrest is an uncommon manifestation of overdose. The present study aimed to evaluate the toxic causes of cardiac arrest in overdosed patients presented to the Toxicology Unit in Mansoura Emergency Hospital in the period between Mars 2008 to Mars 2010. At the end of the study period, forty five cases presented with toxic cardiac arrest. $91.1 \%$ were men ( 41 cases) and $8.9 \%$ were women (4 cases), most of the cases were in age group 20-29 (53.3\%). From all patients history and clinical examination were done, $20 \mathrm{ml}$ urine and $5 \mathrm{ml}$ blood samples were collected. Samples were screened by Enzyme Multiplied Immunoassay Technique (EMIT) and the positive results were confirmed by Thin layer Chromatography (TLC). Tramadol was screened in all urine samples by TLC. The study revealed that the percentages of positive results using EMIT for opiates, cannabinoids, benzodiazepines, barbiturates, ethyl alcohol, tricyclic antidepressants (TCA) and digoxin were $(15.6 \%, 11.1 \%, 68.9 \%, 8.9 \%, 6.7 \%, 11.1 \%$ and $89 \%$ ) respectively. The mean digoxin level was $6.5 \pm 1.29 \mathrm{ng} / \mathrm{ml}$. Six cases were diagnosed by the history and clinical examination as organophosphorus poisoning and confirmed by doing pseudo-choline esterase level with a mean level of $497.75 \pm 149.8 \mathrm{IU}$. Confirmatory testing of positive results by TLC as regards cannabinoids, benzodiazepines, barbiturates and opiates (morphine, codeine and 6 mono-acetyl morphine) were $(11.1 \%),(28.8 \%),(11.1 \%)$ and $(15.5 \%)$ respectively. Tramadol and tramadol coingestions positive results (7 and 12 cases respectively) represented about $42.2 \%$ of all cases. The commonest tramodol co-ingested substance was benzodiazepines (7 cases). In conclusion, the previously declared results revealed that the most common toxic cause of cardiac arrest is tramadol; as drug of abuse; whether used single or co-ingested especially with benzodiazepines. Finally, we recommend increase the scope of drug screen and confirmation methods to cover a big numbers of drugs.
\end{abstract}

Key words: Cardiac Arrest, Acute Overdose, Tramadol, Tramadol Co-ingestions.

\section{INTRODUCTION}

The term drug overdose describes the ingestion or application of a drug or other substance in quantities greater than recommended or generally practiced that may result in a toxic state or death (Bernstein et al., 2007). 
Usage of illicit drugs of unexpected purity, in large quantities, or after a period of drug abstinence can also induce overdose (Hoek et al., 2010).

Accidental overdoses may also be the result of over-prescription, failure to recognize a drug's active ingredient, or accidental ingestion by children (Nelson et al., 2006).

Determination of the substance which has been taken may often be determined by asking the person. However, a search of the home or questioning of friends and family may be helpful if the patients were in altered level of consciousness. Examination for toxidromes, drug testing, or laboratory test surely helpful(Hoek et al., 2010).

Toxic cardiac arrest is an uncommon manifestation of overdose. Although poisoning from many pharmaceuticals and chemicals might eventually lead to cardiac arrest through respiratory failure, asphyxia or hypoxaemia, there are direct myocardial poisons that might particularly be associated with cardiac arrest (Gunja and Graudins, 2011).

The purpose of the present study was to evaluate the toxic causes of cardiac arrest in overdosed patients presented to the Toxicology Unit in Mansoura Emergency Hospital in the period between Mars 2008 to Mars 2010.

\section{PATIENTS AND METHODS}

\section{(1) Patients:}

This study conducted on all cases presented to the Toxicology Unit in Mansoura Emergency Hospital with cardiac arrest due to overdoses from March 2008 to March 2010 as they reached 45 cases at the end of the study period.

\section{(2) Material:}

\section{A) Kits and standards:}

- EMTT ${ }^{\circledR}$ d.a.u. kits (drug abuse in urine) for qualitative analysis of opiates, benzodiazepines, barbiturates, cannabinoids and ethanol (Behring Diagnostics Inc., 1996).

- EMIT tricyclic antidepressant (TCA) assay kit for the qualitative analysis of tricyclic antidepressant in human serum.

- EMIT 2000 kit for quantitative analysis of digoxin in human serum.

- Quimica Clinica Aplicoda peudocholine esterase kit for the quantita. tive analysis of peudo-choline esterase in human serum.

- TLC standards: tramadol hydrochloride, phenobarbital, diazepam, delta 9-tetrahydrocannabinol, opiates (codeine, morphine and 6-mono-acetyl 
morphine) "Vienna International Toxicology Center".

B) Instruments:

- Syva, Solaris S/N 1067 Version 3.00L.

- TLC : Silica gel 60, Aluminum sheets (without fluorescent indicator), pre-coated 25 sheets, $20 \times 20 \mathrm{~cm}$ (Merk Company).

- Spectrophotometer (Unico UV 2100).

\section{(3) Methods:}

a. Thorough history taking from the relatives was done to evaluate age, sex, marital status and residence of the patients.

b. History of the intake and complete medical examination were per formed to determine the other non investigated toxic causes.

c. Urine sampling: after having informed consent from the relatives, 20 $\mathrm{ml}$ urine was obtained from each patient prior to giving any treatment. Each sample was collected in a dry, labeled container (serial number, age, gender of the patient, clinical provisional diagnosis and date of taking the sample).

d- Blood sample: after having informed consent from the relatives, $5 \mathrm{mI}$ of ve- nous blood was obtained from the patients with positive history of TCA, organophosphorus and digoxin poisoning. Each sample was collected in a dry, labeled container without anticoagulant and centrifuged for separation of plasma for TCA assay, pseudo-choline esterase level and Therapeutic Drug Monitoring (TDM) of digoxin.

e. Toxicological analysis:

- Preliminary drug screen test by EMIT system. Each urine sample was screened for cannabinoids, opiates, benzodiazepines, barbiturates, ethyl alcohol according to Standefer and Backer (1991) and Black et al. (1987).

- TCA assay and digoxin level detected by using EMIT assay system of Abbot on blood samples.

- Confirmation of positive results of EMIT by TLC according to Meadway et al. (1998) and George and Braithwaite (1995).

- Testing the tramadol in all cases by TLC according to Meadway et al. (1998).

- Serum pseudo-choline esterase level (IU) according to Ellman et al. (1961).

\section{(4) Statistical analysis:}

Quantitative data were presented as mean \pm standard deviation and qualitative data were presented as number and percentage (SPSS version 16.0). 


\section{RESULTS}

The age of patients ranged from 20 to 55 years with mean of $31.04 \pm 8.46$. The age group of 20-29 years accounting for $53.3 \%$ of the cases followed by age group of $30-38$ years that accounting for $26.6 \%$. Regarding the gender, $91.1 \%$ were men (41 cases) and $8.9 \%$ were women ( 4 cases) (the ratio of men to women was 10.25:1) (Table 1).

As regards the occupation, $64.4 \%$ of cases we:e employee and $35.6 \%$ were non employee. Regarding the marital status, $11.1 \%$ of cases were married and $88.9 \%$ were single. Most of the cases were coming from urban area $(55.6 \%)$ while the others were from ruler area $(44.4 \%)$. Cases were highly educated, moderately educated and non educated in $24.4 \%, 24.4 \%$ and $51.1 \%$ respectively (Table 2).

The percentages of positive results using EMIT for cannabinoids, benzodiazepines, barbiturates, opiates, ethyl alcohol, tricyclic antidepressants (TCA) and digoxin were $(11.1 \%, 68.9 \%, 8.9 \%, 15.6 \%$, $6.7 \%, 6.7 \%$ and $8.9 \%$ ) respectively as shown in table (3). Four cases diagnosed as digoxin poisoning with a mean level of $6.5 \pm 1.29 \mathrm{ng} / \mathrm{ml}$.

Six cases were diagnosed by the history and clinical examination as organophos- phorus poisoning and confirmed by doing peudo-choline esterase level with a mean of $497.75 \pm 149.8 \mathrm{IU}$ (Table 5).

Confirmation of positive results by TLC as regards cannabinoids, benzodiazepines, barbiturates and opiates (morphine, codeine and 6-mono-acetyl morphine) were $(11.1 \%),(28.8 \%),(11.1 \%)$ and $(15.5 \%)$ respectively as shown in table (4) and figure (1\&3).

Positive results of tramadol and tramadol co-ingestions represented about $42.2 \%$ (7 and 12 cases respectively). The commonest tramodol co-ingested substance was benzodiazepines ( 7 cases) as shown table (4) and figure (2\&3).

\section{DISCUSSION}

In the current study, 45 cardiac arrested patients due to toxic causes were evaluated from Mars 2008 to Mars 2011.

The current results revealed that the mean age of patients was $31.04 \pm 8.47$. More than half of these patients were encountered in the age group $20-29(53.3 \%)$ years followed by the age group 30-38 years accounting for $(26.6 \%)$.

These findings supported by (Flaker, 2002; Guo et al., 2002) who stated that the rate of consumption of illicit drug is higher among 18-24 year old males and 
the illicit drug initiation increased steadily from ages $12-21$ years.

Kapusta et al. (2007) stated that there is growing evidence that human adolescence is a period of increased biological vulnerability to the addictive effects of psychoactive substances.

Furthermore the present study revealed that most of the cases were young male $(91.1 \%)$ while the intoxicated females represented about $8.9 \%$ of the cases (the ratio of male to female was 10.25:1).

The current findings are in agreement to the results reported by Fergusson et al. (2008) who determined higher prevalence of substance abuse among men. In addition, Gunja and Graudins (2011) stated that toxic cardiac arrest and intractable haemodynamic compromise because of poisoning are likely to involve younger healthier patients with a greater chance of positive outcome.

Moreover, the current study stated that the majority of cases were employee $(64.4 \%)$, single $(88.9 \%)$, coming from urban area $(55.6 \%)$ and non educated $(51.2 \%)$.

These results are in accordance to the study done by Mohamed et al. (2010) on opiate overdose patients as they showed in their study the majority of cases were single (95\%), they came from urban areas $(80.7 \%)$, and the majority were belonging to low social class $(80 \%)$ but they in contrary found most of their study cases were unemployed $(90 \%)$.

Regarding the toxicological analysis by TLC positive results of cannabinoids, benzodiazepines, barbiturates and opiates (morphine, codeine and 6 mono-acetyl morphine) were $(11.1 \%),(28.8 \%),(11.1 \%)$ and $(15.5 \%)$ respectively.

Wolf et al. (2005) concluded that benzodiazepines have a wide therapeutic index and taken alone in overdose rarely cause severe complications or fatalities. But if taken in combination with alcohol, barbiturates, opioids, tricyclic antidepressants, or sedating antipsychotics, anticonvulsants, or antihistamines are particularly dangerous.

In addition, Sattou and Nicol (2009) explained the cardiovascular manifestations of cannabis as a result from a biphasic dose-dependent physiological effect on the autonomic nervous system: low to moderate doses tend to cause tachycardia and raised blood pressure by increasing the sympathetic activity, whilst high doses produce bradycardia and hypotension by increasing the parasympathetic activity.

In accordance to the current study, Caldicott et al. (2005) who stated that there 
are considerable adverse cardiovascular events linked with cannabis use. Bachs and Morland (2001) observed six cases of acute cardiovascular death after cannabis use. Other reported cardiovascular complications of cannabis included ventricular tachy-arrhythmias and atrial fibrillation (Aryana and Williams, 2007).

In acco:-dance, Di Mizio et al. (2007) as they reported one adult patient with a long history of epilepsy treated with phenobarbital that died suddenly as consequence of cardiac arrest.

Cicero et al. (2005) explained the shift of the opiate abuser to tramadol abuse as:

1. Prescription drugs are relatively easily obtained as opposed to the great difficulty and perceived danger in obtaining heroin and other illicit drugs.

2. The purchase of illicit drugs on the street, such as heroin, was closely monitored by law enforcement officials and arrests were, therefore, far more likely for heroin than for legal drugs, such as opioid analgesics.

3. The use/abuse of prescription drugs is more socially acceptable among peers compared with heroin or cocaine.

4. The purity and the dosage of pre- scription medications are highly predictable, and consequently, they are much safer to use than illicit drugs.

5. When heroin is unavailable, these drugs serve as acceptable, although not preferred, substitutes.

6. These drugs can be useful as selfmedications to relieve symptoms of heroin withdrawal or in an effort to detoxify.

In the present work, organophosphorus poisoning encountered for 6 cases of cardiac arrest while digoxin poisoning was responsible for 4 cases.

The present study was supported by Fukushima et al. (2010) who experienced 20 cases of out-of-hospital cardiac arrest (OHCA) caused by acute intoxication. The causative agents were organophosphates in 8 cases, carbon monoxide in 5 cases, and barbiturates in 3 cases. Other agents were paraquat, tricyclic anti-depressants, lime sulfur, and amphetamine.

Chacko and Elangovan (2010) stated that organophosphate (OP) compounds are commonly used as suicidal agents and produce characteristic toxic effects. They emphasized the importance of being aware of the potential for organophosphate compounds to cause late onset asystole and the need for continued ECG 
monitoring even after the acute symptoms appear to have settled.

Furthermore, the current study revealed that tramadol and tramadol coingestions represented 7 and 12 cases respectively of all cases of cardiac arrest. The commonest tramodol co-ingested substance was benzodiazepines ( 7 cases).

In accordance with the current work, Daubin et al. (2007) as they considered tramadol overdose as one of the most frequent causes of drug poisoning. Although tramadol use is largely considered safe, several lethal cases of tramadol intoxication were reported, suggesting an underestimated toxicity.

In the contrary, Levine et al. (1997) analyzed tramadol distribution in four postmortem cases but did not attribute death to tramadol intoxication.

While, Shadnia et al. (2008) accordingly observed two cases; one male and the second was female; who had both attempted suicide with ingestion of tramadol capsule without any co-ingestion, both patients died following cardiopulmonary arrest.

Clarot et al. (2003) suggested that tram adol overdose, especially when taken in combination with other CNS depressants, such as benzodiazepines, can cause death, even at low dose and advised physicians to be aware of the potential toxic effects when tramadol used with benzodiazepines.

Moreover, Tjaderborn et al. (2007) stated that the main problem in tramadol use is the co-ingestions in which atypical clinical presentations appear as in asystole.

\section{CONCLUSION}

The previously declared results revealed that the most common cause of cardiac arrest among overdosed patients was tramadol especially if co-ingested with benzodiazepines.

\section{RECOMMENDATION}

1- Increase the scope of drug screen and confirmation methods to cover a big numbers of drugs.

2- The thorough investigation for the needs of opiate prescription (among trauma, rheumatic and chronic pain patients) is mandatory because physician may be legally responsible for inducing abuse.

3- Public awareness should be raised by promoting all potential complications associated with drugs and substances use. 
Table (1): Age and gender of patients presented with toxic cardiac arrest $(n=45)$

\begin{tabular}{|c|c|c|c|c|c|c|}
\hline \multirow{2}{*}{ Age group } & \multicolumn{2}{|c|}{$\operatorname{Mcn}(41)$} & \multicolumn{2}{|c|}{ Women (4) } & \multicolumn{2}{|c|}{ Total (45) } \\
\hline & No & $\%$ & No & $\%$ & No & $\%$ \\
\hline $20-29$ & 22 & 53.6 & 2 & 50 & 24 & 53.3 \\
\hline $30-38$ & 12 & 29.2 & - & - & 12 & 26.6 \\
\hline$\geq 39$ & 7 & 17.2 & 2 & 50 & 9 & 20.1 \\
\hline Meant SD & \multicolumn{2}{|c|}{$30.85 \pm 8.32$} & \multicolumn{2}{|c|}{$33.00 \pm 11.1$} & \multicolumn{2}{|c|}{$31.04 \pm 8.46$} \\
\hline
\end{tabular}

Table (2): Demographic data of the studied cases $(n=45)$.

\begin{tabular}{|c|c|c|c|c|c|c|c|}
\hline & & \multicolumn{4}{|c|}{ Gender } & \multicolumn{2}{|c|}{ Total } \\
\hline & & \multicolumn{2}{|c|}{ Male (41) } & \multicolumn{2}{|c|}{ Female (4) } & \multirow{2}{*}{$\begin{array}{l}\text { Frequency } \\
\text { (n) }\end{array}$} & \multirow{2}{*}{$\begin{array}{c}\text { Percentage } \\
(\%)\end{array}$} \\
\hline & & $\mathbf{n}$ & $\%$ & n & $\%$ & & \\
\hline \multirow[t]{2}{*}{ Occupation } & non employee & 13 & 31.7 & 3 & 75 & 16 & $35.6 \%$ \\
\hline & employee & 28 & 68.3 & 1 & 25 & 29 & $64.4 \%$ \\
\hline \multirow{2}{*}{$\begin{array}{l}\text { Marital } \\
\text { status }\end{array}$} & married & 4 & 9.8 & 1 & 25 & 5 & $11.1 \%$ \\
\hline & single & 37 & 90.2 & 3 & 75 & 40 & $88.9 \%$ \\
\hline \multirow[t]{2}{*}{ Residence } & urban & 22 & 53.7 & 3 & 75 & 25 & $55.6 \%$ \\
\hline & rural & 19 & 46.3 & 1 & 25 & 20 & $44.4 \%$ \\
\hline \multirow[t]{3}{*}{ Education } & Highly educated & 9 & 22 & 2 & 50 & 11 & $24.4 \%$ \\
\hline & Moderately educated & 11 & 26.8 & - & - & 11 & $24,4 \%$ \\
\hline & Non-educated & 21 & 51.2 & 2 & 50 & 23 & $51.1 \%$ \\
\hline
\end{tabular}


Table (3): Drugs and substances detected by EMIT in the studied cases.

\begin{tabular}{|l|c|c|c|c|}
\hline \multirow{2}{*}{$\begin{array}{c}\text { Toxicological screening } \\
\text { by EMUT }\end{array}$} & \multicolumn{4}{|c|}{ Total (45) } \\
\cline { 2 - 5 } & \multicolumn{2}{|c|}{ Positive } & \multicolumn{2}{c|}{ Negative } \\
\cline { 2 - 5 } & $\begin{array}{c}\text { Frequency } \\
(\mathbf{n})\end{array}$ & $\begin{array}{c}\text { Percentage } \\
(\%)\end{array}$ & $\begin{array}{c}\text { Frequency } \\
(\mathrm{n})\end{array}$ & $\begin{array}{c}\text { Percentage } \\
(\%)\end{array}$ \\
\hline Cannabinoids & 5 & 11.1 & 40 & 88.9 \\
\hline Benzodiazepines & 31 & 68.9 & 14 & 31.1 \\
\hline Barbiturate & 4 & 8.9 & 41 & 91.1 \\
\hline Opiate & 7 & 15.6 & 38 & 84.4 \\
\hline Ethyl alcohol & 3 & 6.7 & 42 & 93.3 \\
\hline TCA & 3 & 6.7 & 42 & 93.3 \\
\hline Digoxin & 4 & 8.9 & 41 & 91.1 \\
\hline
\end{tabular}

Table (4): Drugs and substances confirmed by TLC in the studied cases.

\begin{tabular}{|c|c|c|c|}
\hline \multirow{2}{*}{\multicolumn{2}{|c|}{$\begin{array}{c}\text { Confirmatory results } \\
\text { by TLC }\end{array}$}} & \multirow{2}{*}{\multicolumn{2}{|c|}{$\frac{\text { Total (45) }}{\text { Positive }}$}} \\
\hline & & & \\
\hline & & \multirow{2}{*}{$\begin{array}{c}\text { Frequency (n) } \\
2\end{array}$} & \multirow{2}{*}{$\begin{array}{c}\text { Percentage (\%) } \\
4.4 \\
\end{array}$} \\
\hline \multirow{3}{*}{ Cannabinoids } & single & & \\
\hline & co-ingest & 3 & 6.6 \\
\hline & total & 5 & 11.1 \\
\hline \multirow{3}{*}{ Benzodiazepines } & single & 3 & 6.6 \\
\hline & co-ingest & 7 & 15.5 \\
\hline & total & 13 & 28.8 \\
\hline \multirow{3}{*}{ Barbiturate } & single & 4 & 8.8 \\
\hline & co-ingest & 1 & 2.2 \\
\hline & total & 5 & 11.1 \\
\hline \multirow{3}{*}{ Opiates } & single & 5 & 11.1 \\
\hline & co-ingest & 1 & 2.2 \\
\hline & total & 7 & 15.5 \\
\hline
\end{tabular}

Table (5): The statistical data of peudo-choline esterase level in the studied cases.

\begin{tabular}{|l|c|}
\hline & Test \\
\cline { 2 - 2 } & Serum psudocholine esterase \\
\hline Mean \pm SD & $497.75 \pm 149.8$ \\
\hline Frequency(n) & 6 \\
\hline Percentage(\%) & 13.3 \\
\hline Reference level (IU) & $1500-3000 \mathrm{IU}$ \\
\hline
\end{tabular}




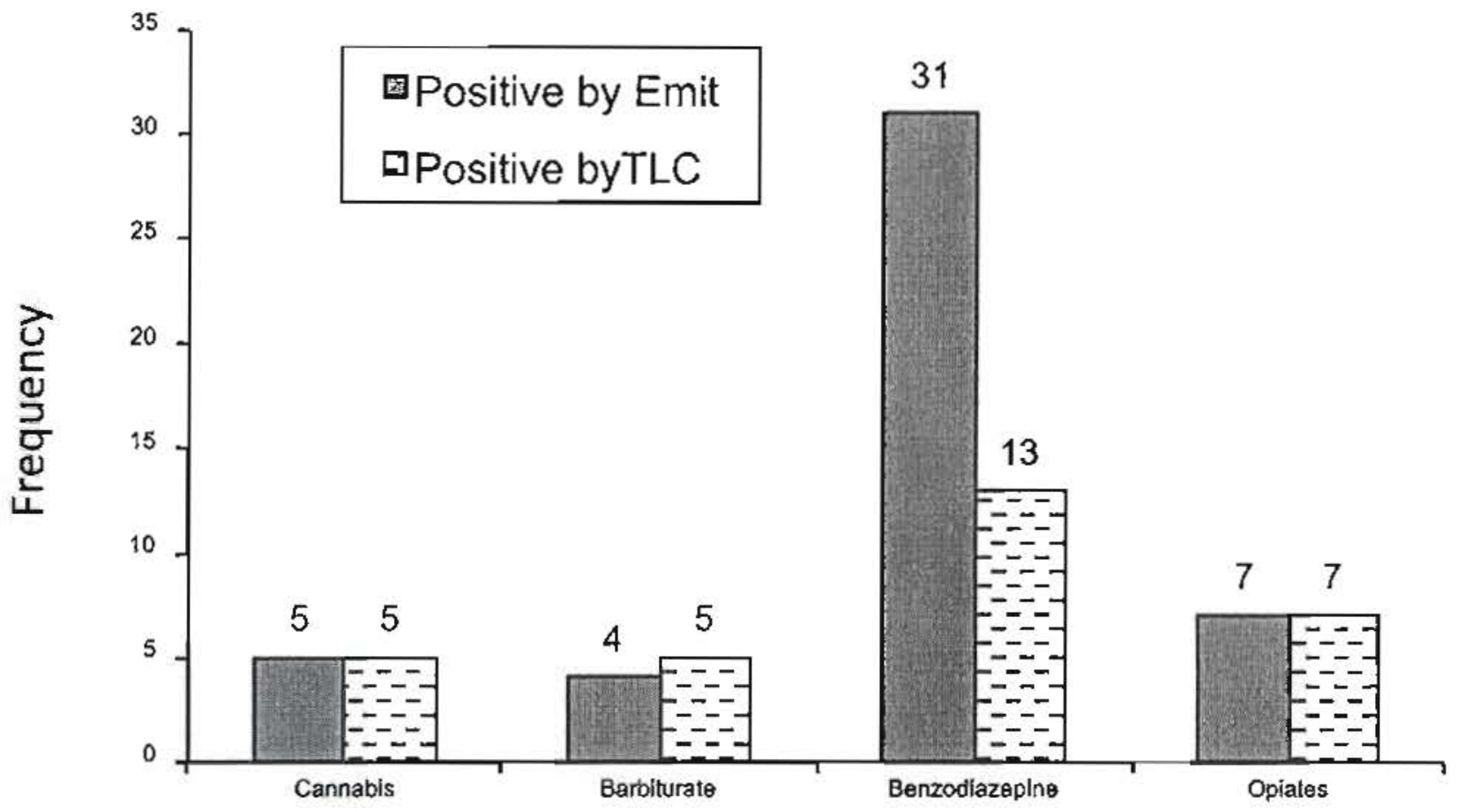

Figure (1): The frequency of substance abuse detected by EMIT and TLC in the studied cases.

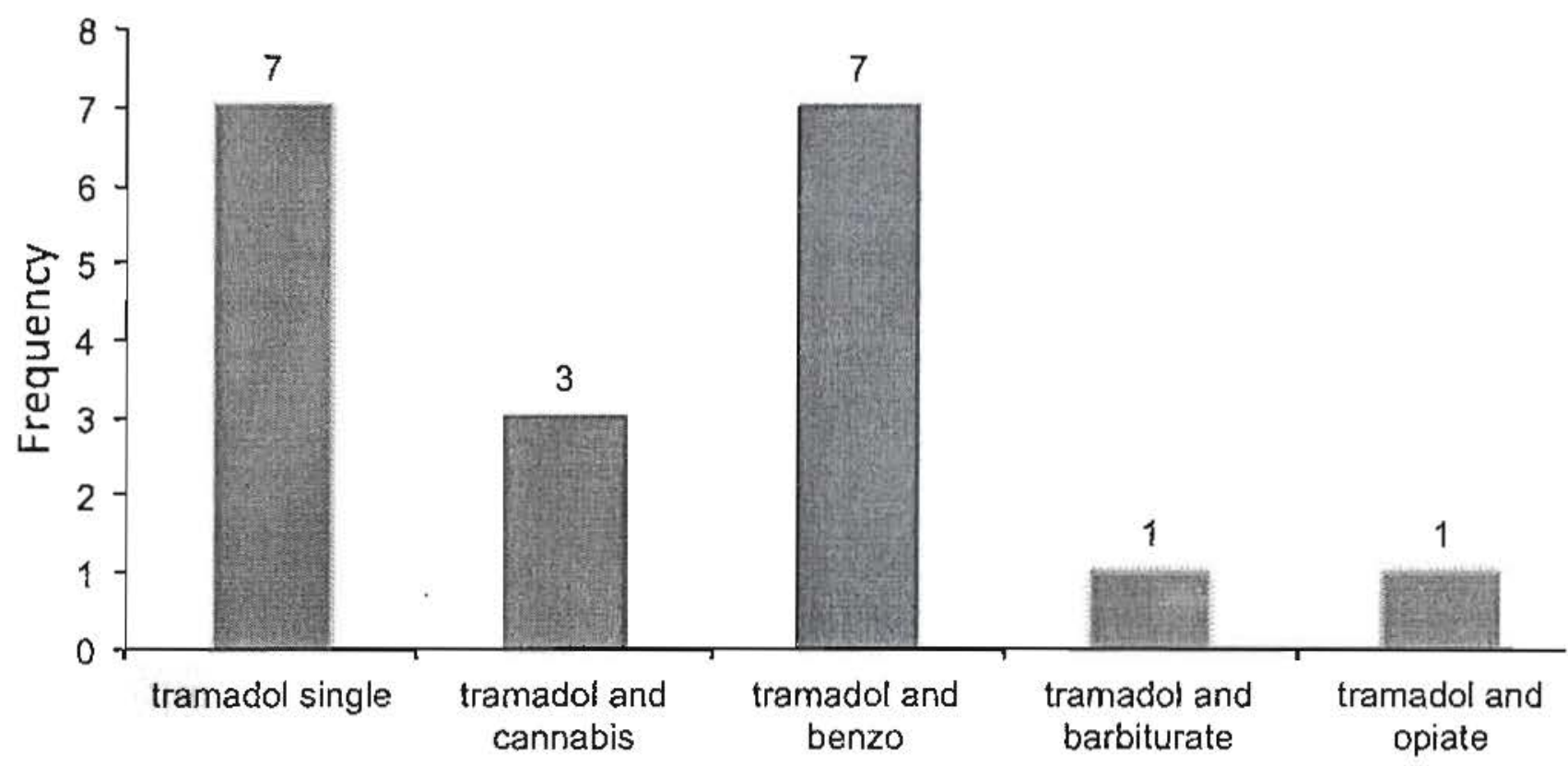

Figure (2): The frequency of tramadol and tramadol co-ingestions detected by TLC in the studied cases. 


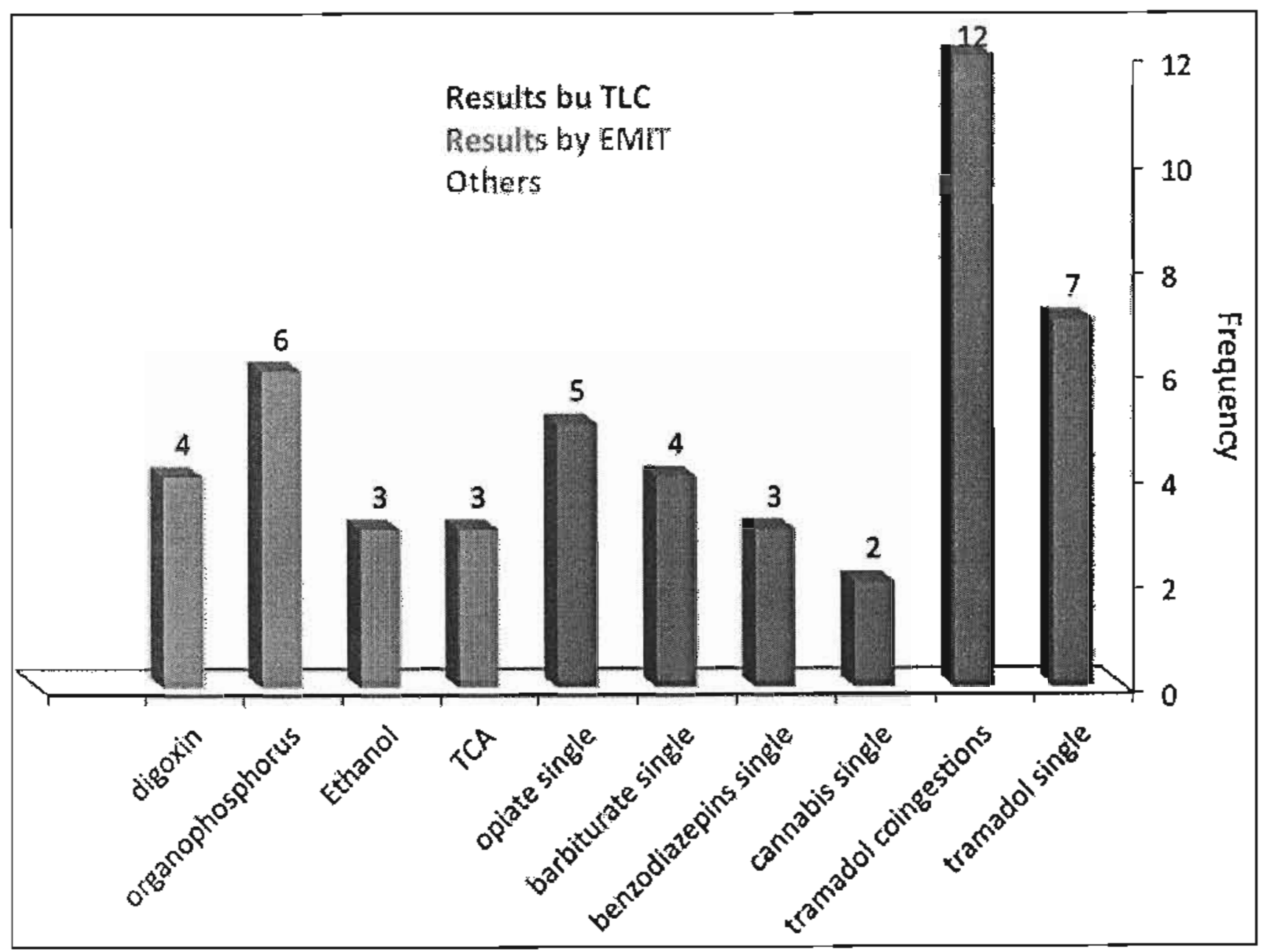

Figure (3): The frequency of the results obtained by history, clinical diagnosis, EMIT and TLC in the studied cases. 


\section{REFERENCES}

Aryana, A. and Williams, M. A. (2007) : "Marijuana as a trigger of cardiovascular events: speculation or scientific certainty". Int. J. Cardiol., 118(2):141-144.

Bachs, L. and Morland, H. (2001) : "Acute cardiovascular fatalities following cannabis use". Forens. Sci. Int., 124(2-3): 200-203.

Behring Diagnostics Inc. (1996) : EMIT $^{\circledR}$ ETS $^{\circledR}$ Plus Ethyl Alcohol Assay. Syva ${ }^{\circledR}$ and Behring diagnostic products. Cupertino, CA 95014.

Bernstein, T. K.; Bucciarelli, A.; Piper, T. M.; Gross, C.; Tardiff, $K$. and Galea, S. (2007) : "Cocaine- and opiate-related fatal overdose in New York City, 1990-2000". BMC Public Health, 7 (31): 1-12.

Black, D. L.; Goldberger, B. A. and Caplan, X. H. (1987) : "Enzyme immunoassay method for comprehensive drug screening in micro-samples of urine". Clin. Chem., 33: $367-371$.

Caldicott, D. G.; Holmes, J.; RobertsThomson, K. C. and Mahar, L. (2005) : "Keep off the grass: marijuana use and acute cardiovascular events". Eur. J. Emerg. Med., 12(5):236-244.

Chacko, J. and Elangovan, A. (2010) :
"Late onset, prolonged asystole following organophosphate poisoning: a case report". J. Med. Toxicol., 6(3): 311-314.

Cicero, T. J.; Inciardi, J. A.; Adams, E. H.; et al. (2005) : "Abuse and physical dependence on ultram, generic tramadol and ultracet in the United States: results of a post-marketing surveillance program: 1994-2004". Pharmaco-Epidemiology and Drug Safety, 14:851-859.

Clarot, F.; Goulle, J. P.; Vaz, E. and Proust, B. (2003) : "Fatal overdoses of tramadol: is benzodiazepine a risk factor of lethality". Forensic Sci. Int., 134: 57-61.

Daubin, C.; Quentin, C.; Goull, J.P.; Guillotin, D.; Lehoux, P.; Lepage, O. and Charbonneau, P. (2007) : "Refractory shock and asystole related to tramadole overdose". Clin. Toxicol. (Phila.), 45 (8):961-964.

Di Mizio, G.; Gambardella, A.; Labate, A.; Perna, A.; Ricci, P. and Quattrone, A. (2007): "Hepatonecrosis and cholangitis related to long term Phenobarbital therapy: an autopsy report of two patients". Seizure, 16(7):653-656.

Ellman, G. L.; Fest, J. S. and Gross, T. L. (1961): "A new and rapid colorimetric determination of acetyl cholinesterase activity". Biochem. Pharmacol., 7: 88 95. 
Fergusson, D. M.; Boden, J. M. and Horwood, L. J. (2008) : "The developmental antecedents of illicit drug use: evidence from a 25-year longitudinal study". Drug and Alcohol Dependence, 96:165-177.

Flaker, V. (2002) : "Heroin use in Solvenia-A consequence or a vehicle of social changes". Eur. Addict. Res., 8:170-176.

Fukushima, H.; Watanabe, T.; Asai, H.; Yada, N.; Ito, S.; Seki, T.; Ueyama, T.; Urizono, Y.; Nishio, K. and Okuchi, K. (2010) : "Out of hospital cardiac arrest caused by acute intoxication". Chudoku Kenkyu., 23(1):41-46.

George, S. and Braithwaite, R. (1995) : "A preliminary evaluation of five rapid detection kits for on site drugs of abuse screening". Addiction, 90: 227-232.

Gunja, N. and Graudins, A. (2011) : "Management of cardiac arrest following poisoning". Emergency Medicine Australasia, 23(1):16-22.

Guo, J; Hill, K. G. and Hawkins, J. D. (2002): "A developmental analysis of sociodemographic, family and peer effects on adolescent illicit drug initiation". J. Am. Acad. Child. Adol. Psychi., 41(7): 838845.

Hoek, V. T. L.; Morrison, L. J.; Shuster, M.; Donnino, M.; Sinz, E.; Lavonas, E. J.;
Jeejeebhoy, F. M. and Gabrielli, A. (2010) : "Part 12: cardiac arrest in special situations: 2010 American Heart Association Guidelines for Cardiopulmonary Resuscitation and Emergency Cardiovascular Care". Circulation, 122 (18 Suppl. 3): 829-861.

Kapusta, N. D.; Plener, P. L.; Schmid, R.; Thau, K.; Walter, H. and Lesch, O. M. (2007) : "Multiple substance use among young males". Pharmacology Biochemistry and Behavior, 86:306-311.

Levine, B.; Ramcharitar, V. and Smialek, J. (1997) : "Tramadol distribution in four postmortem cases". Forensic Sci. Int., 86: $43-48$.

Meadway, C.; George, S. and Braithwaite, R. (1998) : "Opiate concentrations following the ingestion of poppy seed products - evidence for the poppy seed defense". Forensic Sci. Int., 96: 29-38.

Mohamed, H. Y.; Ahmed, S. A. and Fawzi, M. M. (2010) : "Sociodemographic and drug profile of opiate overdosed patients". Int. J. Academic Res., 2 (2): 101107.

Nelson, L. H.; Flomenbaum, N.; Goldfrank, L. R.; Hoffman, R. L.; Howland, M. D. and Neal, A. L. (2006) : Goldfrank's toxicologic emergencies. $8^{\text {th }}$ edition, New York: McGraw-Hill. 
Sattout, A. H. and Nicol, M. F. (2009): "Cardiac arrest following cannabis use: a case report". Cases J., 2(208): 1-3.

Shadnia, S.; Soltaninejad, K.; Heydari, K.; Sasanian, G. and Abdollahi, M. (2008) : "Tramadol intoxication: a review of 114 cases". Human and Experimental Toxicology, 27: 201-205.

Standefer, J. C. and Backer, R. C. (1991): "Drug screening with EMIT reagents: a quantitative approach to quality control". Clin. Chem., 37: 733-738.

Tjäderborn, M.; Jönsson, A. K.; Hägg, S. and Ahlner, J. (2007) : "Fatal unintentional intoxications with tramadol during 1995-2005". Forensic Science International, 173: 107-111.

Wolf, B. C.; Lavezzi, W. A.; Sullivan, L. M.; Middleberg, R. A. and Flannagan, L. M. (2005) : "Alprazolam-related deaths in Palm Beach County". Am. J. Forensic Med. Pathol., 26 (1): 24-27. 


\section{دراسة الأسباب السمية لتوقفه القلب فى هرضي الجرعات الزائدة الهترددين على عستشفى الطوارئ - جامست الهنصورة

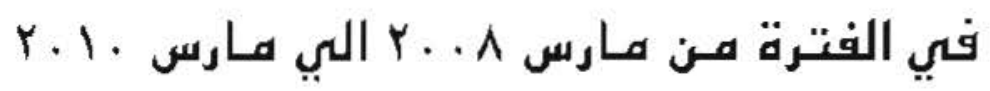

$$
\text { المشتركمن فى البحث }
$$

أ.د. عبد العزيز أبو الفتوح غانمم د. عفاف هـهود عطية . أسامة على شبكة

$$
\text { تسم الطب الشرعى رالسموم الإكلينيكية - كلية الطب - جامعة المنصورة }
$$

إن توتف القلب لأسباب سمية بعتبر عرض غبر مألون. وتد أستهدن البحث تقبيم الأسباب السمية لتوتف القلب بين مرضي الجرعات

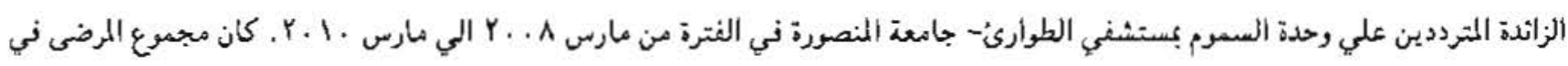

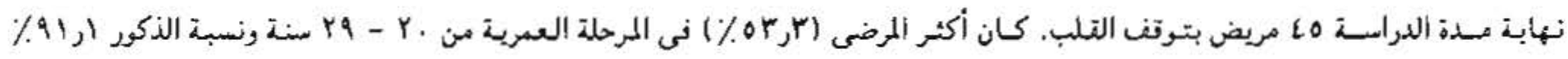

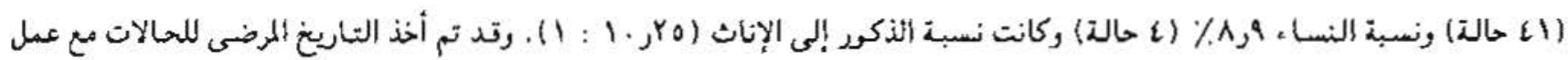

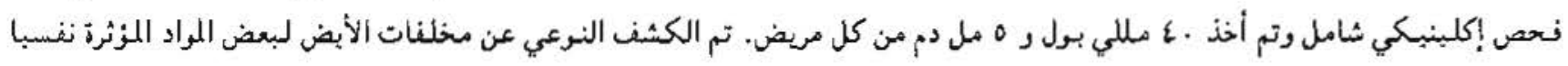

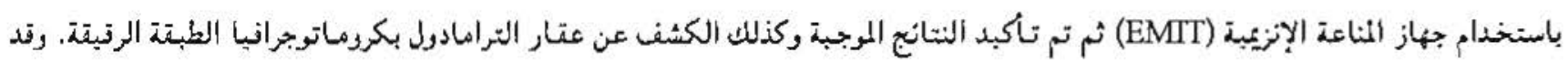

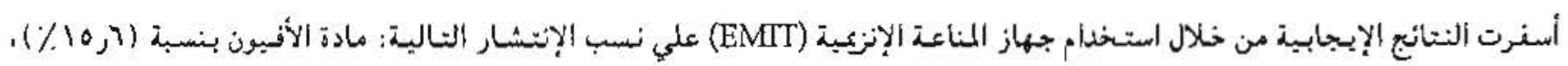

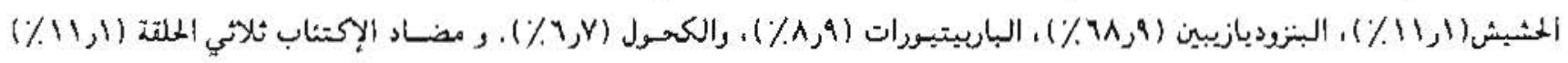

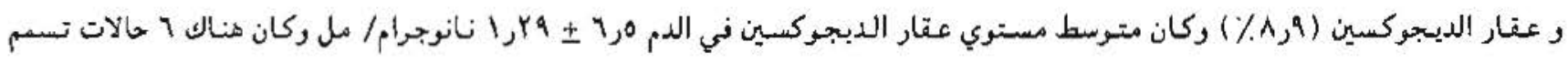

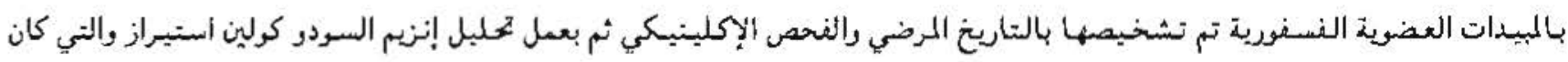

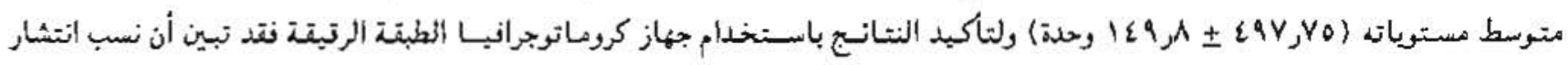

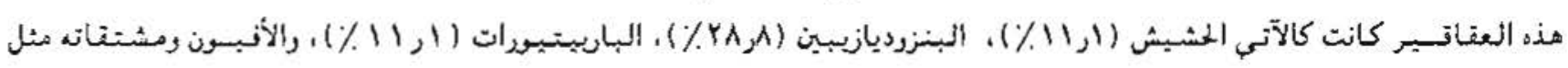

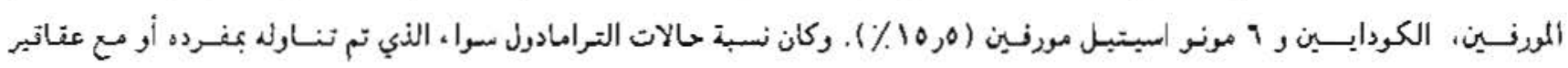

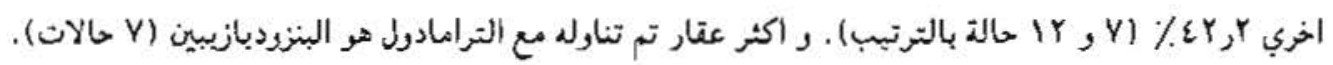

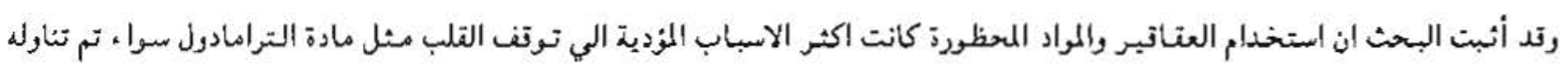

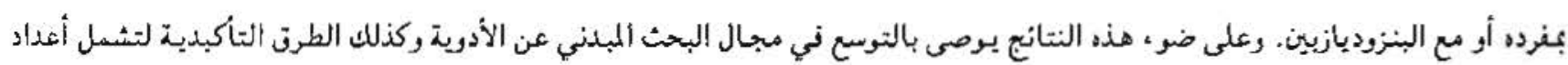
كبيرة من العتاتير. 
